\title{
Partial Discharge Fault Decision and Location of 24kV Composite Porce- lain Insulator based on Power Spectrum Density Algorithm
}

\author{
Shao Zhenhua ${ }^{1, *}$, Sun Zelong ${ }^{2}$, Chen Tianxiang ${ }^{3}$, Chen Li-an ${ }^{4}$, Zheng Mei-rong $^{5}$ \\ ${ }^{1,3,4}$ Department of Electrical Engineering and Automation Xiamen University of Technology, Xiamen City, Fujian Prov- \\ ince, 361024, China \\ ${ }^{2,5}$ Fujian Province Electric Power Maintenance Company, Xiamen City, Fujian Province, 361000, China
}

\begin{abstract}
In order to insure the stability of power grid, $24 \mathrm{kV}$ composite porcelain insulator PD monitoring system is studied in this paper. With the help of pulse current method detection method, the PD propagation characteristics can be precisely recognized by the power spectrum density (PSD). In order to have a good comparison, the PD experiments on $24 \mathrm{kV}$ composite porcelain insulator are in the implementation process under drying conditions. And the comprehensive fault decision based on PSD algorithm is studied in this paper. With the different layer PD faults, the causes and faults can be easily located by PSD algorithm. And the PSD algorithm is introduced in this paper. At last the simulation results show that the proposed method can improve the accuracy and the real-time performance of fault diagnosis in $24 \mathrm{kV}$ composite porcelain insulators.
\end{abstract}

Keywords: Partial discharge, power spectrum density (PSD), fault decision and location, comprehensive fault decision, 24kV composite porcelain insulators, pulse current method (PCM).

\section{INTRODUCTION}

According to power system statistics report, more than $37 \%$ blackouts on power distribution system is caused by insulation failure [1]. Insulation fault in composite porcelain insulators is a potential threat to flight safety of the $24 \mathrm{kV}$ power grid stable operation [2-4]. There is no doubt that composite porcelain insulators play important roles in power transmission. Auto-recognition to discharge types in on-line PD monitoring system could be used to find out internal partial defects and the relevant discharge development degree in time, and then prevents equipment from the coming faults. In general, electromagnetic radiation, high frequency pulse, dielectric loss voice, lighting and heating emitting can be monitored with the profile of PD in power equipment. And there are several PD propagation characteristics method discussed in the references [5-7]. Electric methods and nonelectric methods are to diagnose and correct problem situations for large power transformer. Such as pulse current method (PCM), dielectric loss method (DLM) and electromagnetic radiation method (ERM) have been studied in the past decade. According the IEC standards, PCM is the recommended detection method on PD propagation characteristics.

\subsection{PD Models and Experimental Devices}

According to the internal insulation PD in porcelain insulators and the PD propagation characteristics, there are three

*Address correspondence to these authors at the Department of Electrical Engineering and Automation Xiamen University of Technology, Xiamen City, Fujian Province, 361024, China; Tel: +86 18359224182; E-mail: Szh4h@163.com
PD models designed in this paper, which are shown in Fig. (1) That is point discharge in transformer oil (P1), Solid Insulation of Power Transformer (P2), and surface discharge in transformer oil (P3). The PD signals are measured by PCM. Test PD detection schematic diagram and experimental devices are shown in Fig. (1) and Fig. (2).

\subsection{Power Spectrum Density Analysis}

PSD analysis is the method which indicates the relation between the power change and the frequency variation. The most part of the PSD is the calculation of spectral density function. With the help of PAD analysis, statistical operator, pulse waveform characteristics, and fractal characteristics in 2 dimensions or 3 dimensions can be considered. As can be shown in Equation 1, the frequency of PD and the maximum PD value can be calculated by the different windows spectral density functions (such as Boxcar data sampling, Hamming data sampling and Blackman window data sampling etc.) [8, 9].

$\int_{-\infty}^{+\infty}|S(t)|^{2} d t=\int_{-\infty}^{+\infty}|S(f)|^{2} d f$

\section{EXPERIMENTAL PROCEDURE}

\subsection{PD Experimental Requirements}

In order to have a good contrast effect, starting discharge voltage VS. extinction voltage mode are studied in this experiment. With the study of surface discharge in $24 \mathrm{kV}$ composite porcelain insulators, the source voltage is gradually 

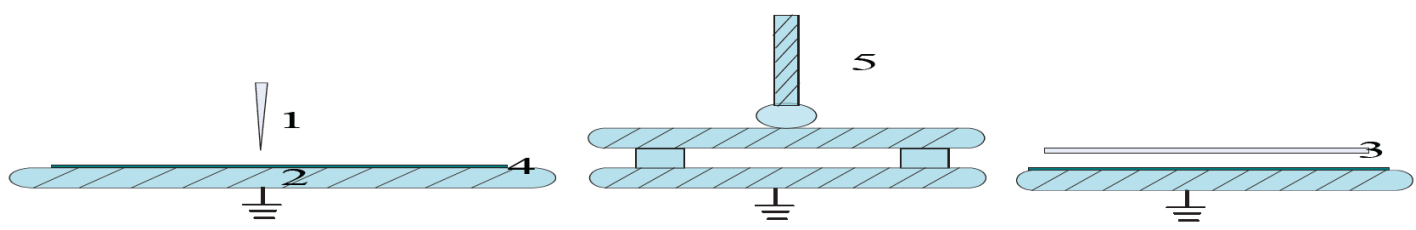

point discharge in transformer oil (P1)Solid Insulation of Power Transformer (P2)surface discharge in transformer oil (P3)

1 needle electrode 2 circular plate electrode 3 plate electrode 4 tank oil 5 ball electrode

Fig. (1). PD models of artificial defects.

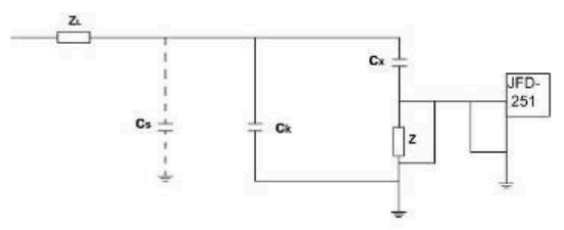

2.a Electric Schematic Diagram

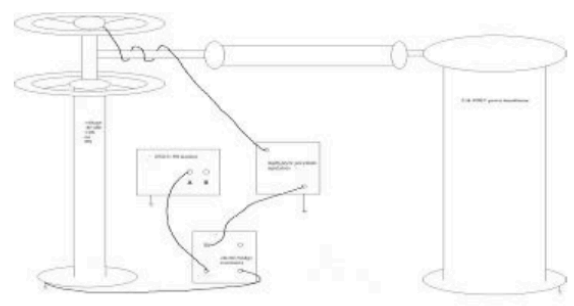

2.b Physical Connected Circuit

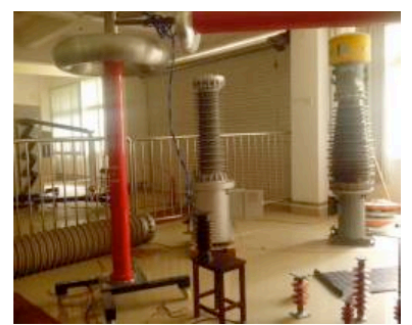

2.c Actual Connection

Fig. (2). Detection Circuit on PD of $24 \mathrm{kV}$ composite Porcelain Insulators.

Table 1. Starting Discharge Voltage VS. Extinction Voltage Under the Drying Condition.

\begin{tabular}{|c|c|c|c|}
\hline Layer Number & Starting Voltage $/ \mathbf{k V}$ & Max Voltage/kV & Extinction Voltage /kV \\
\hline \hline 7 & 52 & 57.9 & 32.7 \\
\hline 6 & 38.8 & 44 & 28.3 \\
\hline 5 & 34.1 & 38.9 & 22 \\
\hline 4 & 28.1 & 32.4 & 15.6 \\
\hline 2 & 24.2 & 28.4 & 10.1 \\
\hline 1 & 18.7 & 22.6 & 8.1 \\
\hline
\end{tabular}

increased by $1 \mathrm{kV}, 2 \mathrm{kV}$ and $3 \mathrm{kV}$ separately. When the surface of $24 \mathrm{kV}$ composite porcelain insulators is under the drying condition, the surface discharge experiments are implemented with different layers from 1 to 7 . Moreover, the starting discharge voltage VS extinction voltage modes are shown in Table 1.

With the study of surface discharge in $24 \mathrm{kV} 7$-layer porcelain insulators the source voltage is gradually increased from 52 to $57.8 \mathrm{kV}$ by $0.48 \mathrm{kV}$ step. In this way, we can get 12PRPD patterns(from $\mathrm{t}=0.1$ to $1.2 \mathrm{~s}$, with time interval of $0.1 \mathrm{~s}$ ) as shown in Fig. (3). In order to have a quick and accurate calculation on power spectrum density, the 3-D colorful 12PRPD patterns are converted to the 2-D gray PD images, as can be shown in Fig. (4). With the help of MATLAB 7.0, the $24 \mathrm{kV}$ composite Porcelain Insulators PSD values in different PRPD gray images of PD can be obtained, which are shown in Fig. (5).

With the consideration of random disturbance and statistical characteristics in different PRPD gray images of PD, the experimental results should be considered in one cycle. Furthermore, the PRPD gray images of PD are also varied with different electromagnetic environments. Compared with Fig. (3) and Fig. (4), we know that the big fluctuation on PRPD patterns may not be the characteristic value for different operation conditions $[10,11]$.

\subsection{PD Data Analysis with PSD Method}

In this way, some classification methods should be considered, such as SVM, fuzzy clustering method and some ANN methods. In this paper, PSD method are proposed in PD data's-analysis.

With help of MATLAB 7.0 and PSD tool, the PRPD gray images of $\mathrm{PD}$ are converted in Fig. (5). As can be seen from the Fig. (5), the PSD mean value and variance value of $24 \mathrm{kV}$ 7-layer Porcelain Insulators are shown in Table 2. When the variance value is more large, the PSD mean value 


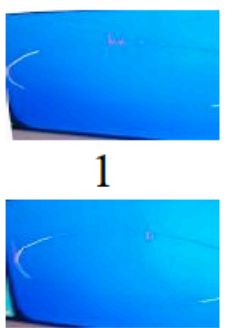

5

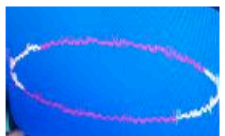

9

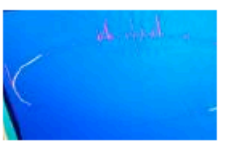

2

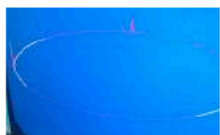

6

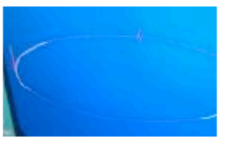

10

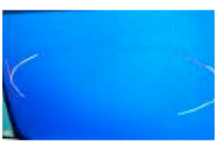

3

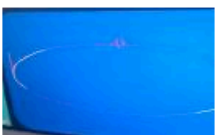

7

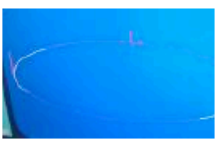

11

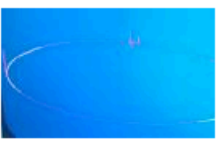

4

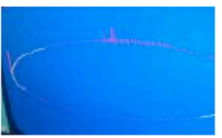

8

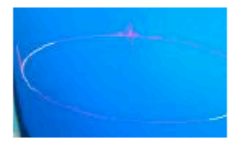

12

Fig. (3). $24 \mathrm{kV}$ composite Porcelain Insulators PRPD patterns of PD (from left to right and from top to bottom, the $0.1 \mathrm{~s}$ to $1.2 \mathrm{~s}$ PRPD patterns under drying condition and layer number $=7$, the same to Fig. 4 and Fig. 5).

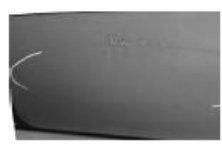

1

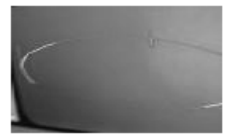

5

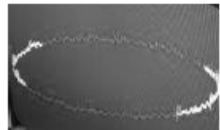

9

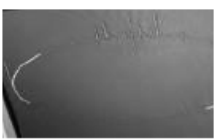

2

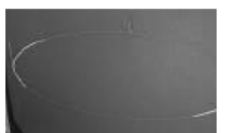

6

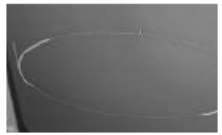

10

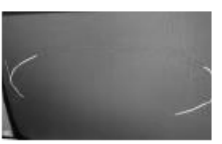

3

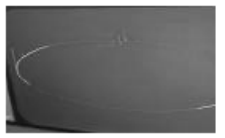

7

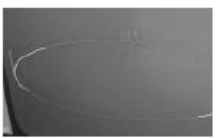

11

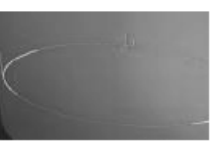

4

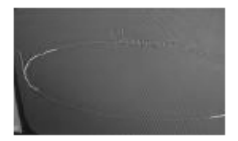

8

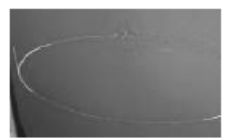

12

Fig. (4). 24kV composite Porcelain Insulators PRPD gray images of PD.
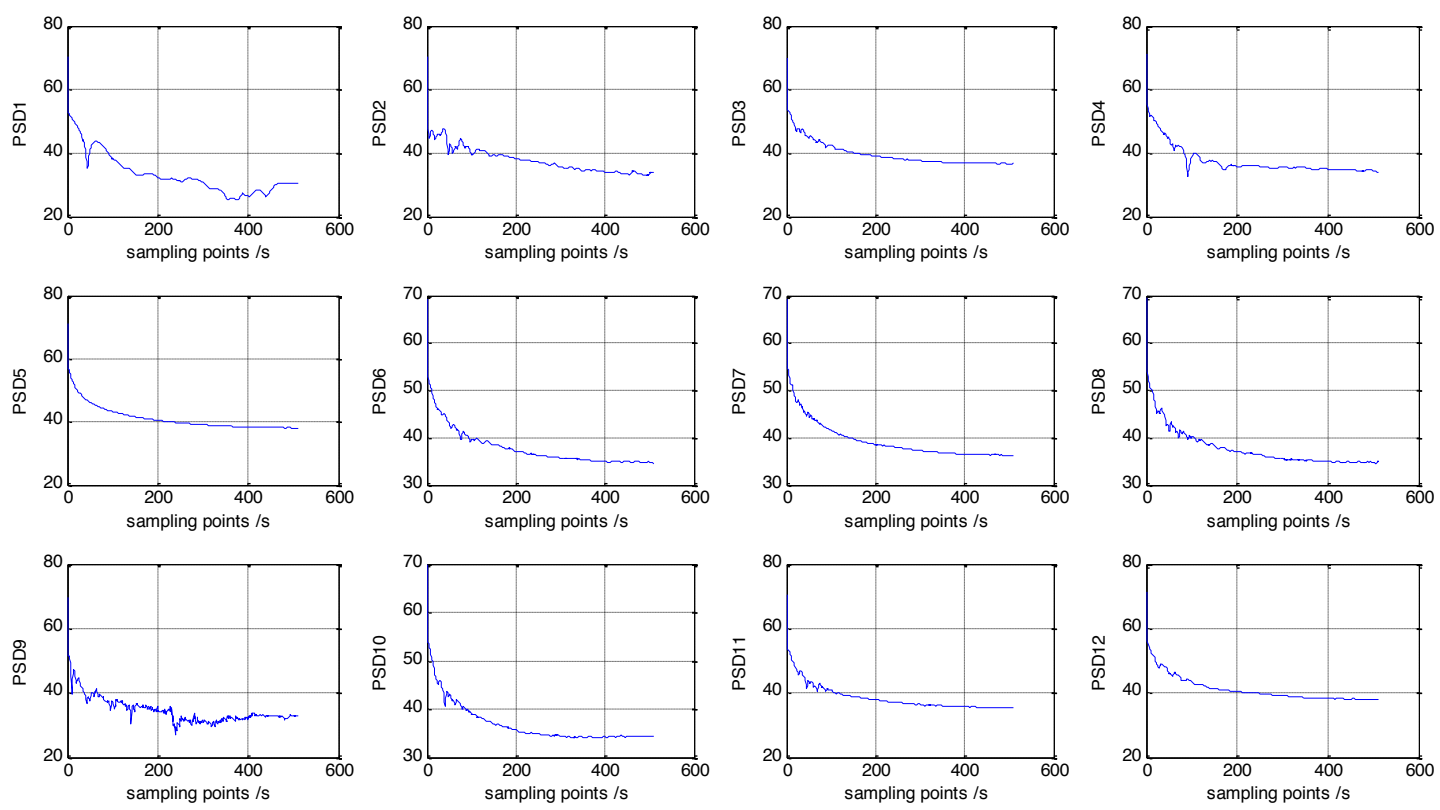

Fig. (5). 24kV composite Porcelain Insulators PSD values in different PRPD gray images of PD. 
Table 2. PSD Mean Value and Variance Value of $24 \mathrm{kV}$ 7-layer Porcelain Insulators.

\begin{tabular}{|c|c|c|c|}
\hline \multicolumn{5}{|c|}{ Mean Value/ Variance Value } \\
\hline \hline K1:33.3163/41.732 & $\mathrm{K} 2: 37.8148 / 17.1364$ & $\mathrm{~K} 3: 39.7116 / 15.717$ & $\mathrm{~K} 4: 37.4712 / 21.3663$ \\
\hline $\mathrm{K} 5: 41.1662 / 16.244$ & $\mathrm{~K} 6: 37.8365 / 16.1358$ & $\mathrm{~K} 7: 39.3415 / 16.0575$ & $\mathrm{~K} 8: 37.7466 / 16.3457$ \\
\hline $\mathrm{K} 9: 34.6511 / 18.3673$ & $\mathrm{~K} 10: 36.8939 / 18.6764$ & $\mathrm{~K} 11: 38.4485 / 15.6617$ & $\mathrm{~K} 12: 41.0732 / 15.6617$ \\
\hline
\end{tabular}

Table 3. PSD and Voltage Increment Curve of Different Layers Porcelain Insulators PRPD Patterns.

\begin{tabular}{|c|c|c|c|c|c|c|c|c|c|c|c|c|c|}
\hline $\begin{array}{l}7 \text { Layer } \\
\text { Voltage }\end{array}$ & Delta Q & $\begin{array}{l}6 \text { layer } \\
\text { Voltage }\end{array}$ & Delta Q & $\begin{array}{l}5 \text { Layer } \\
\text { Voltage }\end{array}$ & Delta $Q$ & $\begin{array}{l}4 \text { Layer } \\
\text { Voltage }\end{array}$ & Delta Q & $\begin{array}{l}3 \text { Layer } \\
\text { Voltage }\end{array}$ & Delta Q & $\begin{array}{c}2 \text { Layer } \\
\mathrm{e}\end{array}$ & Delta Q & $\begin{array}{l}1 \text { Layer } \\
\text { Voltage }\end{array}$ & Delta Q \\
\hline 53 & 0.4 & 39.8 & 0.3 & 35 & 0.25 & 29 & 0.4 & 25 & 0.2 & 20 & 0.2 & 16 & 0.15 \\
\hline 54 & 0.5 & 40.8 & 0.35 & 36 & 0.4 & 30 & 0.45 & 26 & 0.4 & 21 & 0.25 & 17 & 0.2 \\
\hline 55 & 0.55 & 42 & 0.5 & 37 & 0.5 & 31 & 0.48 & 27 & 0.55 & 22 & 0.35 & 18 & 0.3 \\
\hline 56 & 0.6 & 43 & 0.6 & 38 & 0.55 & 32.4 & 0.6 & 28.2 & 0.57 & 22.6 & 0.45 & 19.3 & 0.4 \\
\hline 57 & 0.8 & 44 & 0.7 & 38.9 & 0.65 & 31 & 0.55 & 27 & 0.55 & 22 & 0.4 & 18 & 0.37 \\
\hline 55 & 0.65 & 40 & 0.5 & 35 & 0.45 & 27 & 0.42 & 23 & 0.28 & 18 & 0.3 & 14 & 0.25 \\
\hline 54 & 0.6 & 39 & 0.45 & 34 & 0.4 & 26 & 0.38 & 22 & 0.25 & 17 & 0.28 & 13 & 0.22 \\
\hline 53 & 0.5 & 38 & 0.43 & 33 & 0.3 & 25 & 0.35 & 21 & 0.22 & 16 & 0.25 & 12 & 0.2 \\
\hline 52 & 0.4 & 37 & 0.4 & 32 & 0.29 & 24 & 0.3 & 20 & 0.2 & 15 & 0.24 & 11 & 0.15 \\
\hline 51 & 0.3 & 36 & 0.35 & 31 & 0.28 & 23 & 0.2 & 19 & 0.18 & 14 & 0.2 & 10 & 0.15 \\
\hline
\end{tabular}

is more variable with voltage fluctuation. And the results have more typical resolution on patterns of PD, except the special changes on the first data and the fourth data (which is shown with yellow color background).

As can be concluded according to the Table 2 and equation 2, the mean PRPD gray images value can be obtained (M stands for typical value of PSD):

$$
\begin{aligned}
& M=\frac{1}{9}(k 2+k 3+k 5+k 6+k 7+k 8+ \\
& k 9+k 10+k 11+12)
\end{aligned}
$$

where $\mathrm{K} 1$ and $\mathrm{K} 4$ are singular value for the calculation of PSD values. Then the PSD and Voltage Increment curve of 7 and 6 layers porcelain insulators PRPD patterns can be shown in Fig. (6).
As can be seen form the Fig. (6), PSD and Voltage Increment curve of different layer porcelain insulators PRPD patterns have different PSD values. in this way, we can locate the position and the value of PD faults. The detailed data are shown in Table 3.

\section{CONCLUSION}

In this paper, the comprehensive fault decision based on PSD algorithm is studied. Furthermore, the PD experiments on $24 \mathrm{kV}$ composite porcelain insulator are in the implementation process under drying conditions and the PSD values are obtained by image recognition. With the help of MATLAB 7, he simulation results show that the proposed method can improve the accuracy and the real-time performance of fault diagnosis in $24 \mathrm{kV}$ composite porcelain insulators. 

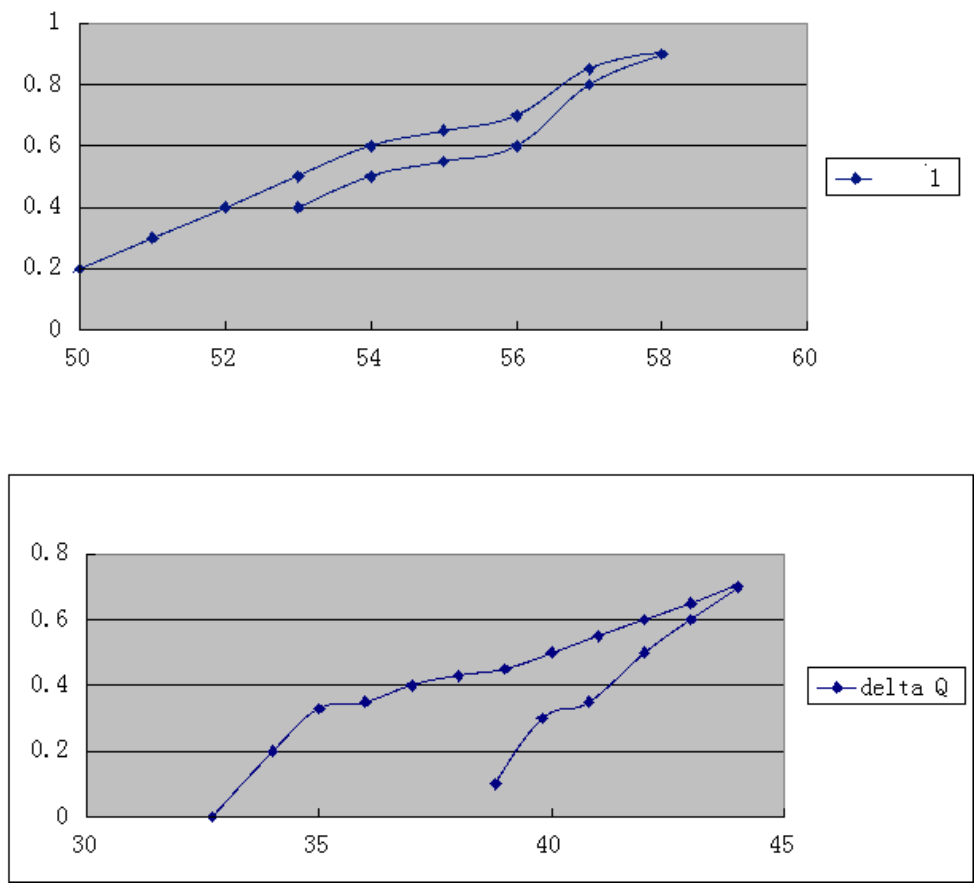

Fig. (6). PSD and voltage increment curve of 7 layer and 6 layer porcelain insulators PRPD patterns (delta $Q$ : $Y$-axis ,U :X-axis).

\section{CONFLICT OF INTEREST}

The authors confirm that this article content has no conflict of interest.

\section{ACKNOWLEDGEMENTS}

The Project Supported by Fujian Provincial Major Scientific and Technological Projects under grant 2014H6028, Scientific Research Items of XMUT under grant XYK201401, XMUT Initializing Foundation under grant YKJ12010R, and Fujian Natural Science Foundation under grant 2016J01267.

\section{REFERENCES}

T.C. Green, J.H. Marks, "Control techniques for active power filters," IEE Procedings, vol. 125, no. 2, pp. 369-381, 2005.

H.M. John, and T.C. Green, "Predictive Transient-Following Control of Shunt and Series Active Power Filters," IEEE Transactions On Industrial Electronics, vol. 17, no. 4, pp. 574-583, 2002.

J. W. Dixon, and B. T. Ool, "Indirect current control of a unity power factor sinusoidal current boost type three-phase rectifier," IEEE Trans. on Industrial Electronics, vol. 35, no. 4, pp. 508-515, 1998.

Y. A.R. I. Mohamed, and E. F.EI-Saadany, “An Improved Deadbeat Current Control Scheme With a Novel Adaptive Self-Tuning
Load Model for Three-Phase PWM Voltage-Source Inverter," IEEE Transactions On Industrial Electronics, vol. 54, no. 2, pp. 747-758, 2007.

[5] W. Yi, "Birkhoff normal forms for the wave equations with nonlinear terms depending on the time and space variables," Computer Modeling and New Technologies, vol. 18, no. 4, pp. 42-49, 2014

[6] S. Satieo, R. Devaraj, and D. A. Torrey, "The design and implementation of a three-phase active power filter based on sliding mode control," IEEE Trans. on Industrial Application, vol. 31, no. 5, pp. 993-999, 1995.

[7] R. Ding, C. Ma, Y. Zhao, Y. Lu, and J. Liu,“Anti-synchronization of a class of fractional-order chaotic system with uncertain parameters," Computer Modeling and New Technologies, vol. 18, no. 11, pp. 109-112, 2014

[8] B. N. Singh, B. Shigh, A. A. Chandra, "Active power filter with sliding mode control," IEE. Proc. Generation A Transmission and Distribution, vol. 144, no. 6, pp. 564-568, 1997.

[9] J. M. E. Huerta, J. Castello-Moreno, J. R. Fischer, and R. GarciaGil, "A Synchronous Reference Frame Robust Predictive Current Control for Three-Phase Grid-Connected Inverters," IEEE Transactions On Industrial Electronics, vol. 57, no. 3, pp. 954-961, 2010.

[10] P. Cortes, A. Wilson, S. Kouro, J. Rodriguez, and H. Abu-Rub, "Model Predictive Control of Multilevel Cascaded H-Bridge Inverters," IEEE Transactions On Industrial Electronics, vol. 57, no. 8, pp. 2692-2698, 2010.

[11] W. Tang, J. Wu, and M. Liu, "Interleaving semantics and action refinement in event structures," Computer Modeling and New Technologies, vol. 18, no. 6, pp. 44-51, 2014. 